\title{
Tunable Covalent Triazine-Based Frameworks (CTF-0) for Visible- Light-Driven Hydrogen and Oxygen Generation from Water Splitting
}

\author{
Dan Kong, ${ }^{\dagger}$ Xiaoyu Han, ${ }^{\dagger}$ Jijia Xie, ${ }^{\dagger}$ Q Qiushi Ruan, ${ }^{\dagger}$ Christopher D. Windle, ${ }^{\dagger}$ Srinivas Gadipelli, ${ }^{\dagger}$

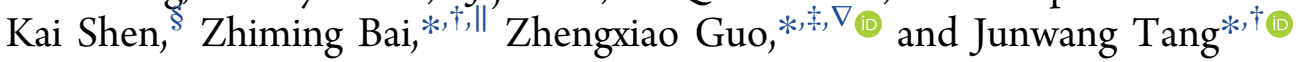 \\ ${ }^{\dagger}$ Department of Chemical Engineering, University College London, Torrington Place, London, WC1E 7JE, United Kingdom \\ ${ }^{\ddagger}$ Department of Chemistry, University College London, 20 Gordon Street, London, WC1H 0AJ, United Kingdom \\ ${ }^{\S}$ Department of Electronic and Electrical Engineering, University College London, Torrington Place, London WC1E 7JE, United \\ Kingdom \\ "School of Materials Science and Engineering, Beihang University, No. 37 Xueyuan Road, Haidian District, Beijing 10019, China
}

Supporting Information

ABSTRACT: Covalent triazine-based frameworks (CTFs), a group of semiconductive polymers, have been identified for photocatalytic water splitting recently. Their adjustable band gap and facile processing offer great potential for discovery and development. Here, we present a series of CTF-0 materials fabricated by two different approaches, a microwave-assisted synthesis and an ionothermal method, for water splitting driven by visible-light irradiation. The material $\left(\mathrm{CTF}-0-\mathrm{M}_{2}\right)$ synthesized by microwave technology shows a high photocatalytic activity for hydrogen evolution (up to $7010 \mu \mathrm{mol}$ $\mathrm{h}^{-1} \mathrm{~g}^{-1}$ ), which is 7 times higher than another (CTF-0-I) prepared by conventional ionothermal trimerization under identical photocatalytic conditions. This leads to a high turnover number (TON) of 726 with respect to the platinum cocatalyst after seven cycles under visible light. We attribute this to the narrowed band gap, the most negative conduction band, and the rapid

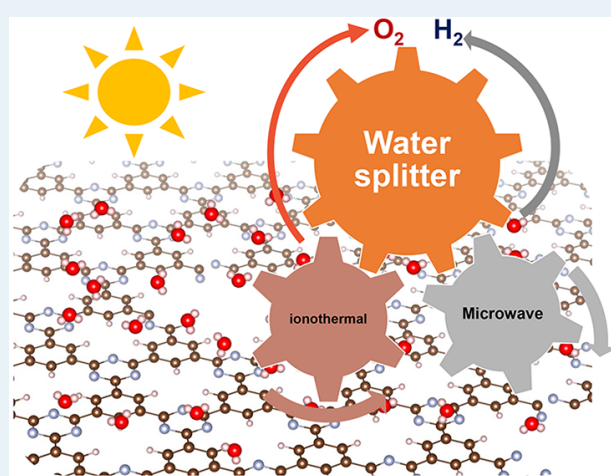
photogenerated charge separation and transfer. On the other hand, the material prepared by the ionothermal method is the most efficient one for oxygen evolution. CTF-0-I initially produces ca. 6 times greater volumes of oxygen gas than CTF-0-M 2 under identical experimental conditions. CTF-0-I presents an apparent quantum efficiency (AQY) of $5.2 \%$ at $420 \mathrm{~nm}$ for oxygen production without any cocatalyst. The activity for water oxidation exceeds that of most reported CTFs due to a large driving force for oxidation and a large number of active sites. Our findings indicate that the band positions and the interlayer stacking structures of CTF-0 were modulated by varying synthesis conditions. These modulations impact the optical and redox properties, resulting in an enhanced performance for photocatalytic hydrogen and oxygen evolution, confirmed by firstprinciples calculations.

KEYWORDS: covalent triazine-based frameworks, oxygen evolution, hydrogen evolution, visible-light-driven photocatalysis, water splitting

\section{INTRODUCTION}

Conversion of simple molecules into chemical fuels by artificial photosynthesis via solar energy is an environmentally friendly way of producing clean sustainable power and to reduce greenhouse gas emissions. ${ }^{1}$ More specifically, visible-lightdriven water splitting into $\mathrm{O}_{2}$ and $\mathrm{H}_{2}$ by photocatalysis shows promising potential to realize solar-to-chemical energy conversion in practice. ${ }^{2}$ For overall water splitting, single semiconductor photocatalysts have been reported to generate hydrogen and oxygen successfully and simultaneously from water under light illumination in a suspension system. ${ }^{3}$ However, the highest quantum efficiency of a single photocatalyst for overall water splitting has been reported to be $2.5 \%$ at $420-440 \mathrm{~nm}$ on $\left(\mathrm{Ga}_{1-x} \mathrm{Zn}_{x}\right)\left(\mathrm{N}_{1-x} \mathrm{O}_{x}\right),{ }^{4}$ which is much lower than that of a Z-scheme system, e.g., the $\mathrm{SrTiO}_{3}: \mathrm{La}, \mathrm{Rh} /$ $\mathrm{Au} / \mathrm{BiVO}_{4}$ :Mo photocatalyst sheet, which exhibits an apparent quantum efficiency of $33 \%$ at $419 \mathrm{~nm}{ }^{5}$ A Z-scheme system can yield much higher efficiency than a single photocatalyst for several reasons. Redox mediators in Z-schemes can enhance charge separation and mitigate the issue of back reactions often occurred in single photocatalyst systems. The photocatalysts in $\mathrm{Z}$-scheme systems usually required narrower band gaps than a single photocatalyst because the band edges are dedicated to one half-reaction. ${ }^{6}$ Thus, only certain oxides and (oxy)nitrides

Received: May 27, 2019

Revised: July 15, 2019

Published: July 16, 2019 

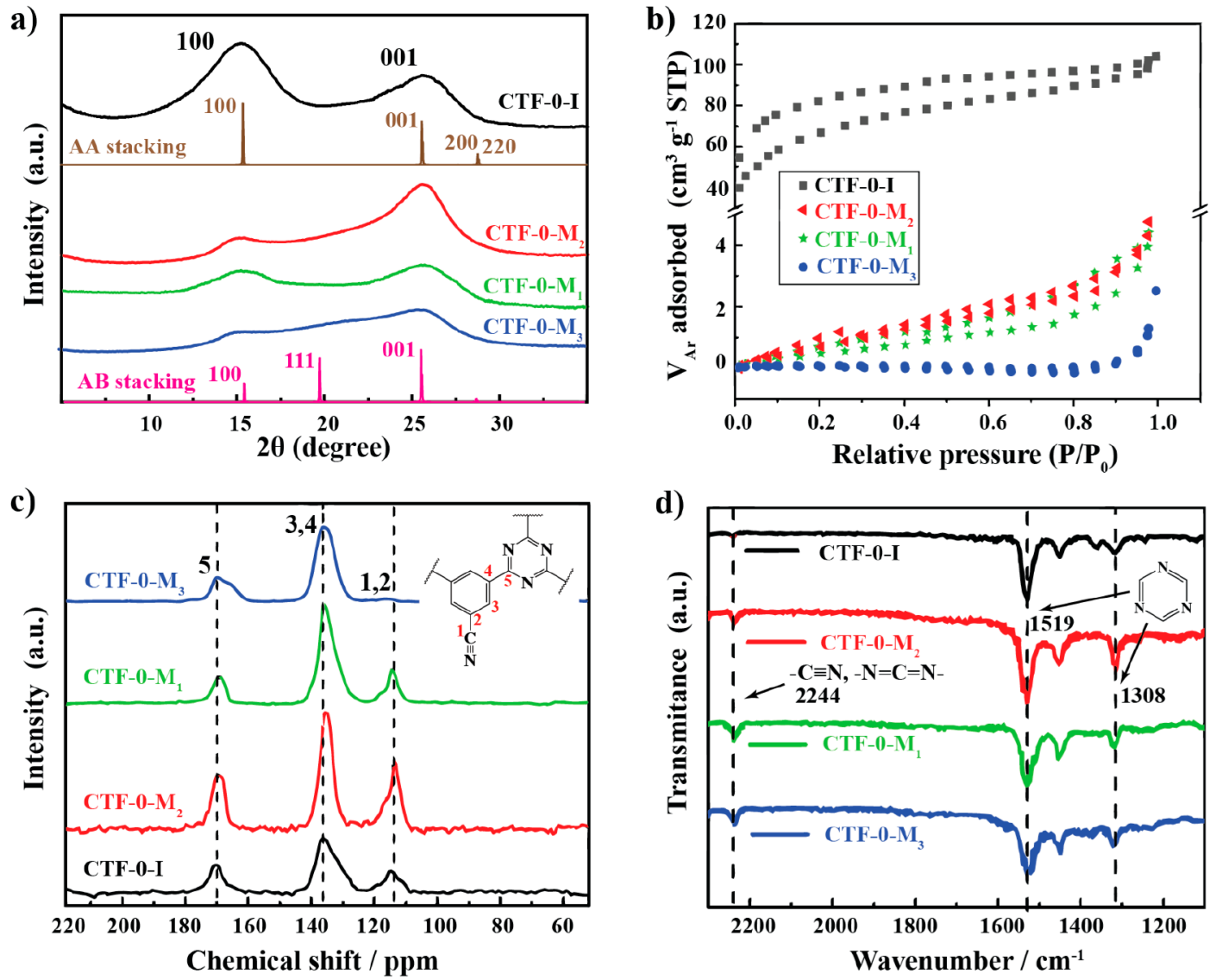

Figure 1. (a) PXRD patterns and calculated based on $\mathrm{AB}$ - and AA-stacking motif, (b) isothermal argon absorption measurements at $87 \mathrm{~K}$, (c) ${ }^{13} \mathrm{C}$

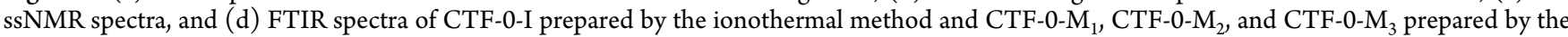
microwave method.

can be used as single photocatalysts for overall water splitting, while many narrow-bandgap semiconductors can be potentially used in Z-scheme systems. ${ }^{7}$ Furthermore, photoelectrochemical (PEC) water splitting also demonstrates a high solar-tohydrogen conversion efficiency, such as $\sim 3.3 \%$ for overall water splitting at neutral $\mathrm{pH}$ over double-band $\mathrm{GaN}: \mathrm{Mg}$ / InGaN:Mg nanosheet photochemical diodes. ${ }^{8}$ Moreover, for safety reasons, a strategy for in-situ separation of $\mathrm{H}_{2}$ and $\mathrm{O}_{2}$ is preferable, ${ }^{6}$ which can be achieved in either PEC or Z-scheme systems, but is rather difficult in a single-photocatalyst suspension system. The prerequisite for both PEC and Zscheme systems is an efficient photocatalyst for a half-reaction, either proton reduction or water oxidation. Therefore, many studies concentrate on the discovery of efficient photocatalysts for each half-reaction, as combining these may be a more facile route to overall water splitting (e.g., by Z-scheme) than discovering one single photocatalyst.

Inorganic photocatalysts, such as metal oxides ${ }^{9-13}$ and metal (oxy)nitrides, ${ }^{14,15}$ have been widely explored for the hydrogen evolution reaction. However, the majorities only respond to ultraviolet (UV) irradiation ${ }^{14}$ or present moderate activity due to fast charge recombination. ${ }^{15-18}$ Very recently, conjugated polymers have drawn considerable attentions due to their appropriate conduction band positions and readily tunable electronic structures. Photocatalytic hydrogen generation has been widely investigated over these conjugated polymers such as graphitic carbon nitride $\left(\mathrm{g}-\mathrm{C}_{3} \mathrm{~N}_{4}\right),{ }^{18-23}$ poly(triazine imide), ${ }^{24}$ and other relevant triazine-based networks. ${ }^{25-27}$
Such polymer photocatalysts possess delocalized $\pi$-bonds, which provide established pathways for charge-carrier transport and present high efficiencies for hydrogen evolution. However, the activities for photocatalytic water oxidation over such reported polymers were limited by the valence band positions. Covalent triazine-based frameworks (CTFs) were predicted to show a greater driving force for water oxidation than $\mathrm{g}_{-} \mathrm{C}_{3} \mathrm{~N}_{4}{ }^{16,26}$ Moreover, the photocatalytic activities of CTFs can be enhanced by modifying chemical and physical properties through the selection of different monomers and the adjustments in the synthesis processes. ${ }^{28,29}$ Typically, CTFs can be synthesized by ionothermal trimerization of carbonitrile groups, such as 1,4-dicyanobenzene (DCB), ${ }^{30}$ 1,3,5-tris(4cyanophenyl)benzene (TCPB), ${ }^{31}$ and 2,6-dicyanopyridine (DCP), ${ }^{32}$ where a molten zinc salt was used as a solvent and catalyst at temperatures over $400{ }^{\circ} \mathrm{C}$. Recently, a microwaveassisted approach was applied to prepare crystalline CTFs, P1M-P6M, in trifluorosulfonic acid at $110{ }^{\circ} \mathrm{C} .{ }^{33}$ Our previous work already illustrated that a microwave-prepared CTF-1 photocatalyst for two half-reactions of water splitting. ${ }^{34}$ However, the efficiency is still quite moderate. To change the ratio of nitrogen to carbon in such a polymer will tune its electronic structure as the valence band edge of triazinecontaining polymers is dominated by the nitrogen $2 \mathrm{p}$ orbitals, which shift the band positions that largely affect the photocatalytic activity. ${ }^{34}$

Among all reported CTFs, CTF-0 possesses the highest nitrogen to carbon ratio and only contains alternating benzene 
and triazine units. It can therefore provide more active sites (triazine units) for oxidation reactions. ${ }^{35}$ However, the photocatalytic activity for either half-reaction over CTF-0 has not been experimentally investigated, although first-principles calculations have predicted that a monolayer CTF-0 contained suitable band positions for both of the two half-reactions. ${ }^{35}$ Furthermore, different stacking between layers would result in the interlayer coupling of either $\mathrm{C}-\mathrm{C}$ (AA stacking) or $\mathrm{C}-\mathrm{N}$ ( $\mathrm{AB}$ stacking), which could affect the band edge alignments to the benefit of either half-reaction. ${ }^{35}$ Herein, we utilized different synthesis strategies to optimize the triazine to benzene ratio and the interlayer stacking to systematically study the relationship between photocatalyst structure and photocatalytic activity for both hydrogen and oxygen evolutions on CTF-0. CTF-0-M $\mathrm{M}_{2}$ synthesized by a microwave-assisted method at low temperature presents more $\mathrm{AB}$ stacking orientation and the highest nitrogen to carbon ratio, resulting in the highest photocatalytic activity for hydrogen evolution among all studied. In parallel, CTF-0-I prepared by the ionothermal trimerization method possesses more AAstacking tendency and the lowest nitrogen to carbon ratio, thus presenting the best water oxidation performance. We further confirmed this important correlation between photocatalytic activity, band alignment, and charge dynamics by diverse spectroscopies and theoretical modeling.

\section{RESULTS AND DISCUSSION}

CTF-0 photocatalysts were synthesized by a microwaveassisted approach (CTF-0-M $\mathrm{M}_{1}$ CTF-0-M $\mathrm{M}_{2}$, and CTF-0-M $\mathrm{M}_{3}$ ) and an ionothermal method (CTF-0-I) as indicated in Scheme $\mathrm{S} 1$. The structures of the as-synthesized photocatalysts were characterized by powder X-ray diffraction (PXRD) spectroscopy as shown in Figure 1a. All of the samples have some degree of the extended order. ${ }^{26,36}$ The degree of crystallinity can be optimized by adjusting the ratio of catalyst (trifluoromethanesulfonic acid) and monomer (1,3,5-tricyanobenzene) during microwave-assisted synthesis. CTF-0-M $\mathrm{M}_{2}$ with a precursor to acid catalyst ratio close to $1: 3$ presents the highest degree of crystallinity, which is further proved by the TEM image as shown in Figure S1. Either decreasing or increasing the monomer to acid ratio results in a lower degree of crystallization. Two distinct peaks are located at $\sim 15^{\circ}$ and $\sim 25.5^{\circ}$ in the PXRD patterns of all samples. The low-angle peak at $\sim 15^{\circ}$ can be attributed to the in-plane reflection (100) of the hexagonal unit cell, while the broad peak at $\sim 25.5^{\circ}$ can be interpreted as the interlayer spacing (001) with vertically stacked sheets of $3.4 \AA^{30,31}$ The relative intensities of (100) and (001) in the samples synthesized via the two different methods are reverse. CTF-0-M $\mathrm{M}_{2}$ shows a relatively high intensity of (001), whereas the CTF-0-I is the (100), Figure 1a. Compared with our calculated PXRD based on the AB- and AA-stacking models (Figure S2), denoted in the brown and pink lines in Figure 1a, such PXRD patterns suggest that CTF$0-\mathrm{M}_{2}$ and CTF-0-I possess $\mathrm{AB}$ and $\mathrm{AA}$ stacking, respectively, which is in line with previous theoretical calculations. ${ }^{35,37}$ The $\mathrm{AB}$-stacking possesses a lower formation energy than the AA stacking by $0.03 \mathrm{eV}$ per unit cell. Hence, it is suggested that the CTF-0 tends to form AA stacking at high temperature and over a long period of time as in the ionothermal method and $A B$ stacking in the low temperature and fast microwave approaches, namely, microwave irradiation targets a lower energy stacking structure with a $\mathrm{C}-\mathrm{N}$ interlayer coupling, while the ionothermal method facilitates the reorganization of monomers with $\mathrm{C}-\mathrm{C}$ interlayer coupling.

The porosity of the CTFs was studied by isothermal adsorption experiments at $87 \mathrm{~K}$ by probing with argon as shown in Figure 1b. All samples (CTF-0-M1, -2, and -3) synthesized by the microwave method show a very low argonaccessible surface area of 2,5 , and $0.5 \mathrm{~m}^{2} \cdot \mathrm{g}^{-1}$, respectively. The CTF-0-I shows a comparably loose organic network with an apparent BET surface of $201 \mathrm{~m}^{2} \cdot \mathrm{g}^{-1}$, which is likely owing to some decarboxylation processes and the production of a small amount of gas during the synthesis at high temperature, consistent with previous reports when polymerization is at higher temperatures. ${ }^{31}$ As the carbonization is hard to avoid in the current high-temperature ionothermal approach, the generated surface area is high while it plays a minor role in the activity enhancement.

As shown in Figure $1 \mathrm{c}$, the ${ }^{13} \mathrm{C}$ solid-state nuclear magnetic resonance (ssNMR) provides information on the chemical structure of CTF-0 materials. Three distinct peaks can be assigned to the unreacted cyano groups and the neighboring carbon in the benzene rings (117 ppm), carbon atoms in benzene rings (138 ppm), as well as carbon atoms in triazine units $(169 \mathrm{ppm}){ }^{28,34}$ The peak at $117 \mathrm{ppm}$ of CTF-1-M 3 shifts to a low field, resulting in a shoulder peak located at ca. 165 ppm which can be assigned to the $\mathrm{C}, \mathrm{N}$ alternating heterocyclic units due to incomplete trimerization. This can be caused by the low concentration of monomers in the acidic solvent during microwave-assisted synthesis, which is consistent with the PXRD result of the lowest degree of crystallinity in CTF-0$M_{3}$. Moreover, Fourier-transform infrared spectroscopy (FTIR) further confirms the successful trimerization in all samples, as shown in Figure 1d. Two peaks located at 1308 and $1519 \mathrm{~cm}^{-1}$ correspond to the triazine units, and a very small peak at $2244 \mathrm{~cm}^{-1}$ points to the terminal nitrile groups, incompletely formed $-\mathrm{N}=\mathrm{C}=\mathrm{N}-$ groups, or other uncertain multibonded $\mathrm{C}, \mathrm{N}$ groups. ${ }^{31,38} \mathrm{CTF}-0$-I presents the lowest signal intensity in the FTIR $\left(2244 \mathrm{~cm}^{-1}\right)$ for nitrile groups likely due to some hydrolysis and further decarboxylation when removing the $\mathrm{Zn}$-containing impurities, which is consistent with the higher surface area of CTF-0-I than the other samples as shown in Figure $1 b$.

The elemental composition of all of the samples was analyzed by X-ray photoelectron spectroscopy (XPS) and elemental analysis (EA) as shown in Figures S3-S7 and Table S1, respectively. Both XPS and EA confirm that all samples are composed only of carbon, nitrogen, and hydrogen. The $\mathrm{C} 1 \mathrm{~s}$ XPS measurements of the four samples reveal two peaks as shown in Figure S4. The first signal at $284.8 \mathrm{eV}$ is attributed to the carbon atoms of the aromatic rings as well as adventitious carbon $(\mathrm{C}-\mathrm{C})$ which was used for calibrating the XPS machine. $^{28}$ The second one appears at around $288.2 \mathrm{eV}$, assigned to the $\mathrm{sp}^{2}$-bonded carbon in the triazine rings. The high-resolution N1s XPS spectra of these samples are shown in Figure S5; the peaks located at around $399 \mathrm{eV}$ are associated with the $\mathrm{N}$ atoms in the triazine rings in all samples. It also shows some difference of the peak shape among different samples, which is consistent with the results of ${ }^{13} \mathrm{C}$ ssNMR and FTIR, indicating a different degree of crystallinity. We also confirm that there is no detectable zinc residue in CTF-0-I by XPS (Figures S6 and S7). As XPS is a surface-sensitive technique, EA measurements were used to quantify the elemental compositions (Table S1). The C:H:N ratio of 
a)

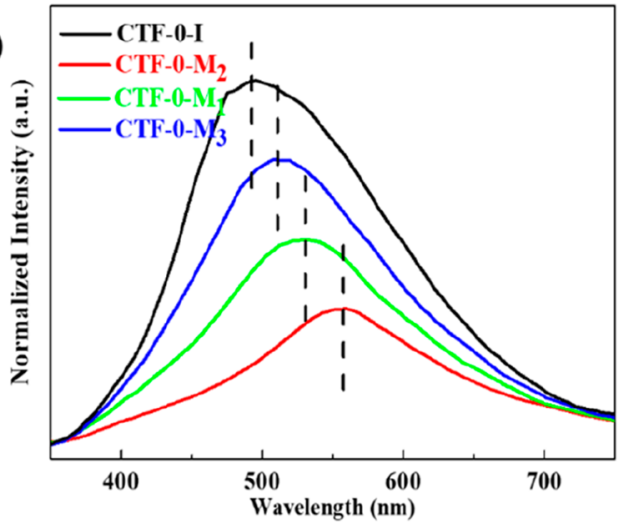

c)

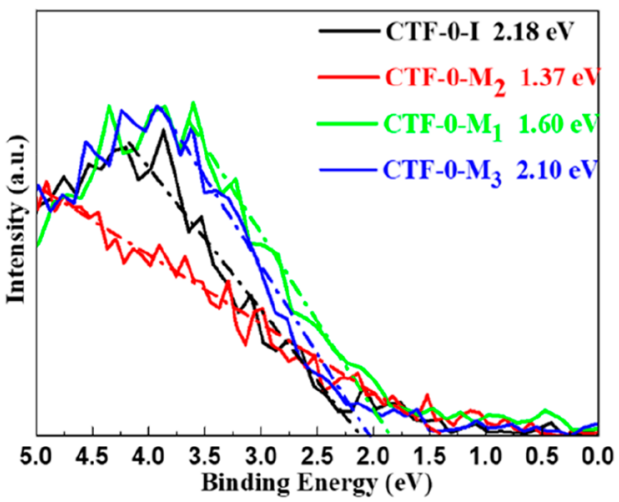

b)

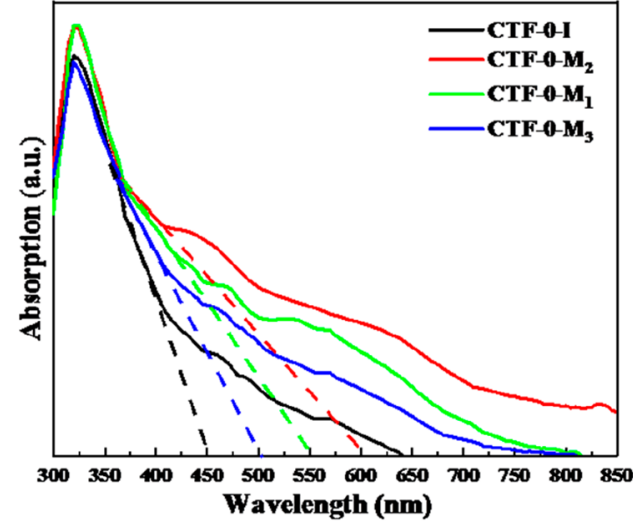

d)

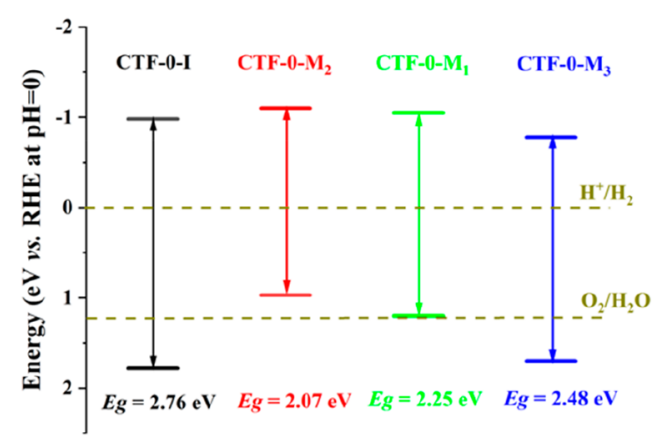

Figure 2. (a) Photoluminescence spectra, (b) UV-vis absorption spectra, (c) valence-band XPS spectra, and (d) experimentally estimated band structure diagrams of CTF-0-I, CTF-0-M $\mathrm{M}_{1}$ CTF-0-M $\mathrm{M}_{2}$ and CTF-0-M .

CTF-0- $\mathrm{M}_{2}$ is $71.4: 2.0: 26.3$, which is among all of the samples the closest to the theoretical value of $70.6: 2.0: 27.4$.

To further investigate the optical properties and derive their band positions, photoluminescence spectra (PL), UV-vis diffuse reflectance spectroscopy, and valence-band XPS spectra were recorded as shown in Figure 2. The emission peaks in the PL spectra are blue shifted following the trend of CTF-0-I > CTF-0-M $M_{3}>$ CTF-0-M $>$ CTF-0-M . Notably, the carbon to nitrogen ratio shares the same trend according to the elemental analysis (Table S1), which indicates that the higher the nitrogen to carbon ratio, the smaller the band gap. ${ }^{39}$ The charge kinetics was verified by time-resolved photoluminescence (Figures S8-S10). As shown in Figure S10a, the fitting results show no significant difference between the three time constants for all four samples, indicating the radiative recombination pathways fundamentally unchanged among samples. The calculated average electron lifetime as shown in Table S2 indicates the better charge separation on samples synthesized by microwave than those fabricated by the ionothermal method with the CTF- $0-\mathrm{M}_{2}$ being the second best. $^{40,41}$

The UV-vis absorbance spectrum is shown in Figure $2 \mathrm{~b}$. It reveals that the absorption edges for CTF-0-I, CTF-0-M, CTF-0-M $M_{1}$, and CTF- $0-M_{3}$ are located at around 450, 600, 550 , and $500 \mathrm{~nm}$, respectively, which is consistent with the trend of the maximum peak position of the PL as shown in Figure 2a. In addition, the materials CTF-0-Ms prepared by the microwave method show an enhancement in visible-light absorption compared to the CTF-0-I. According to the positions of the absorption edges shown in Figure $2 \mathrm{~b}$, the band gaps of each material were calculated to be 2.76, 2.07,
2.25, and $2.48 \mathrm{eV}$ for CTF-0-I, CTF-0-M $\mathrm{M}_{2}$ CTF-0-M $\mathrm{M}_{1}$, and $\mathrm{CTF}-0-\mathrm{M}_{3}$, respectively. To estimate the relative band positions and valence band maximum (VBM), XPS spectra were collected. Figure $2 \mathrm{c}$ presents the different offsets in the binding energies of the valence electrons. CTF-0- $\mathrm{M}_{2}$ presents the most negative valence band edge, and CTF-0-I shows the largest valence band offset. The difference between the two materials is ca. $0.8 \mathrm{eV}$. The valence band offsets of CTF-0-M and CTF-0- $\mathrm{M}_{3}$ are 0.5 and $0.1 \mathrm{eV}$ more negative than CTF-0-I. In a typical XPS measurement, the binding energy of an electron represents the energy that the electron requires to occupy the Fermi level of the XPS analyzer. The work function of the XPS analyzer is ca. 4 (vs vacuum) and $-0.4 \mathrm{eV}$ (vs RHE at $\mathrm{pH}=0) .^{42}$ Thus, the valence band positions of CTF-0-I, CTF-0-M $\mathrm{M}_{2}$ CTF-0-M $\mathrm{M}_{1}$, and CTF-0-M $\mathrm{M}_{3}$ versus RHE at $\mathrm{pH}=0$ can be estimated of ca. $+1.78,+0.97,+1.20$, and $+1.70 \mathrm{eV}$ (vs $\mathrm{RHE}$ at $\mathrm{pH}=0)$, respectively. Given the band gap obtained from UV-vis spectra as shown in Figure $2 b$ and the XPS valence electron spectra, the conduction band positions were calculated as $-0.98,-1.10,-1.05$, and $-0.78 \mathrm{eV}$ (vs RHE at $\mathrm{pH}=0$ ), respectively, for CTF-0-I, CTF-0-M, CTF-0-M $\mathrm{M}_{1}$, and $\mathrm{CTF}-\mathrm{O}-\mathrm{M}_{3}$. Therefore, the band positions of all polymer photocatalysts are shown in Figure 2d. It should be noted that CTF-0-M $\mathrm{M}_{2}$ and CTF-0-M $\mathrm{M}_{1}$ possess the highest conduction band potentials and thus provide greater driving force for the hydrogen evolution reaction, while the valence band edges of CTF-0-I and CTF-0-M $\mathrm{M}_{3}$ are the lowest, benefiting the water oxidation reaction. The change of the band positions can be attributed to the interlayer coupling of valence electrons due to the different stacking (e.g., AA stacking for CTF-0-I and AB stacking for CTF-0-M $\mathrm{M}_{2}$, ${ }^{33}$ the triazine to benzene ratio, and 
a)

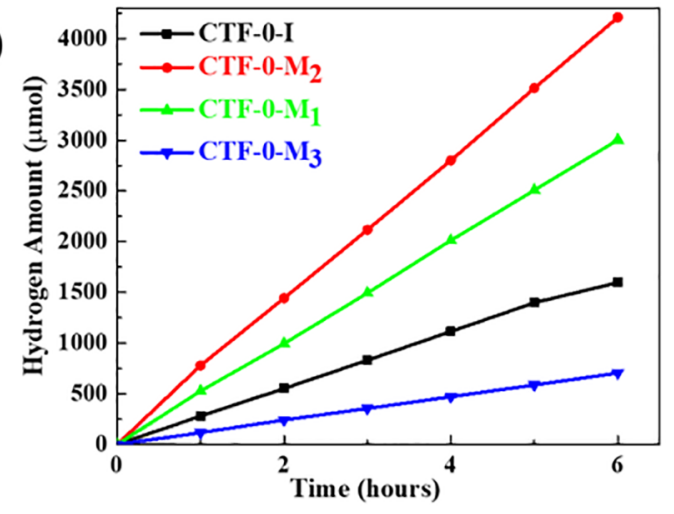

c)

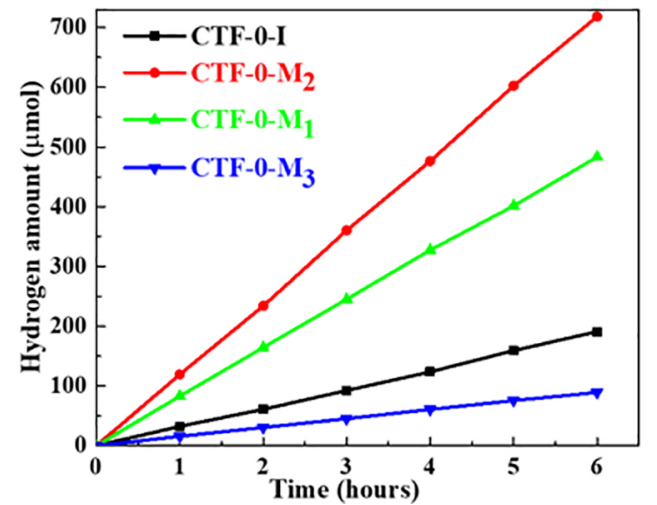

b)

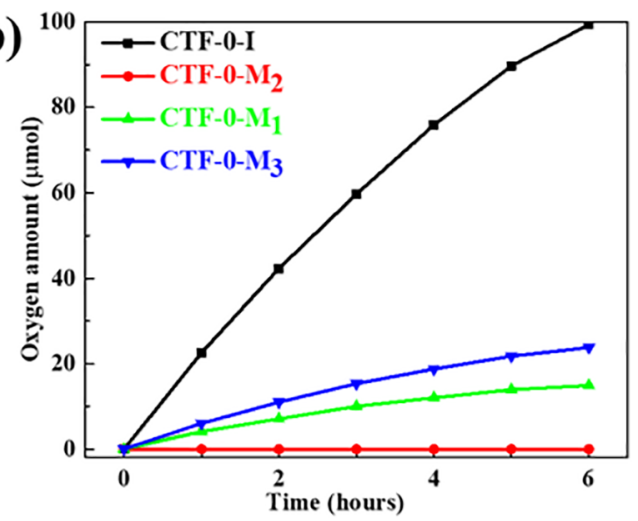

d)

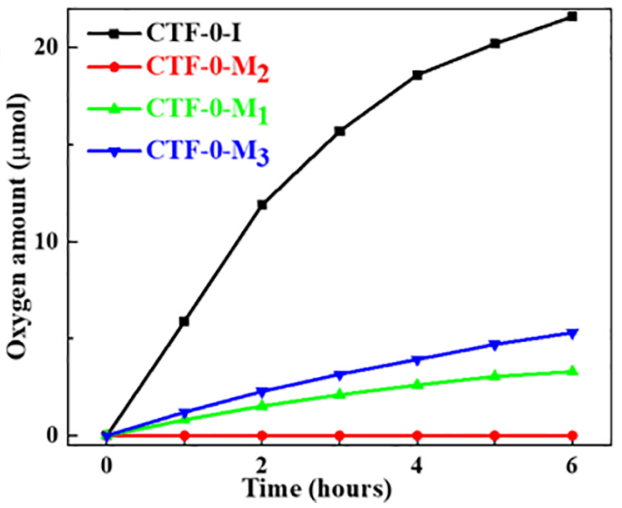

Figure 3. Photocatalytic tests with the as-prepared CTF-0-I and CTF-0-Ms. Time course of $\mathrm{H}_{2}$ evolution and $\mathrm{O}_{2}$ evolution under full arc (a and b) and under visible-light irradiation $(\lambda>420 \mathrm{~nm})(\mathrm{c}$ and $\mathrm{d}) ; 0.1 \mathrm{~g}$ of photocatalyst was used for these tests.

a)

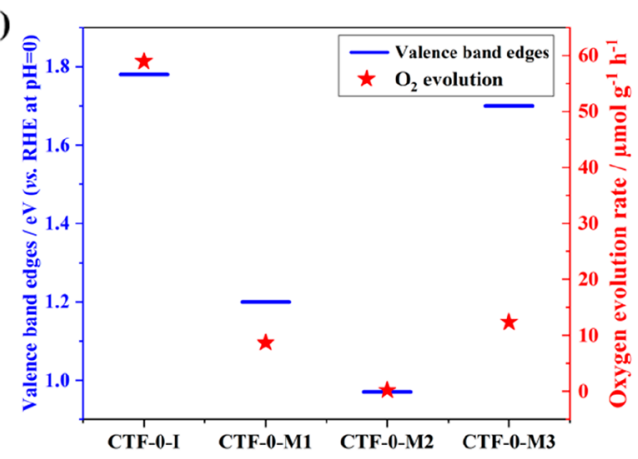

c)

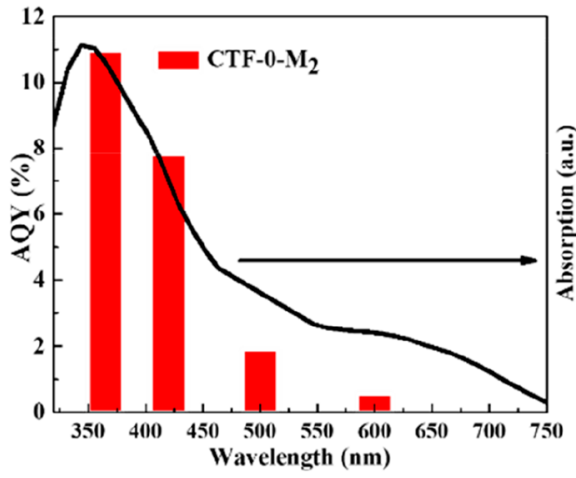

b)
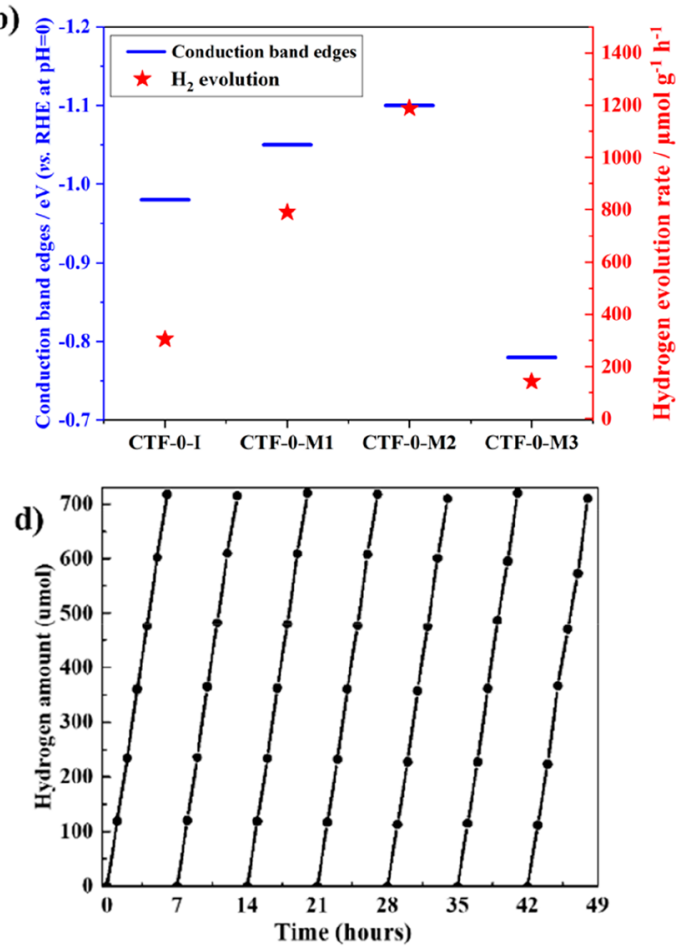

Figure 4. (a) Valence band edge position and $\mathrm{O}_{2}$ production rate and (b) conduction band edge position and $\mathrm{H}_{2}$ amount produced by all photocatalysts under visible irradiation. (c) Apparent quantum yield (AQY) for $\mathrm{H}_{2}$ production. (d) Stability test of CTF-0-M $\mathrm{M}_{2}$ for $\mathrm{H}_{2}$ evolution under ambient conditions with visible-light irradiation $(\lambda>420 \mathrm{~nm})$.

the type of terminal groups (e.g., nitrile terminals in CTF-0- $\mathrm{M}_{2}$ and heterocycle terminals in CTF-0-M 3 ). ${ }^{43}$
The photocatalytic activity for hydrogen and oxygen evolution were then tested as shown in Figure 3. The 
(a)

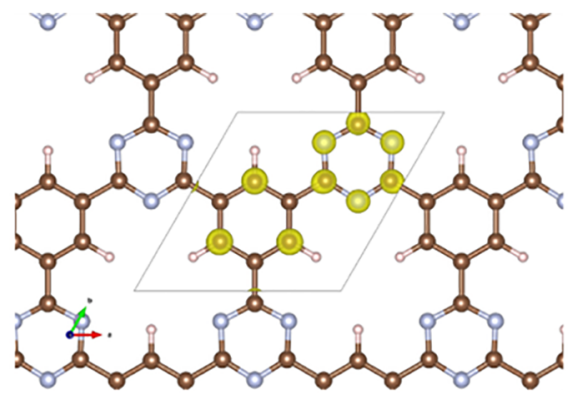

(b)

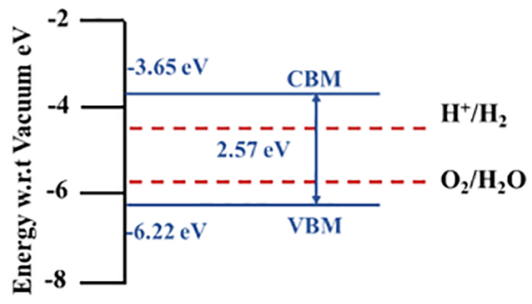

(c)

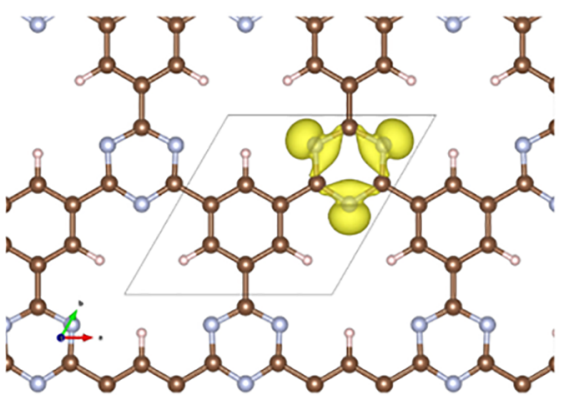

(d)

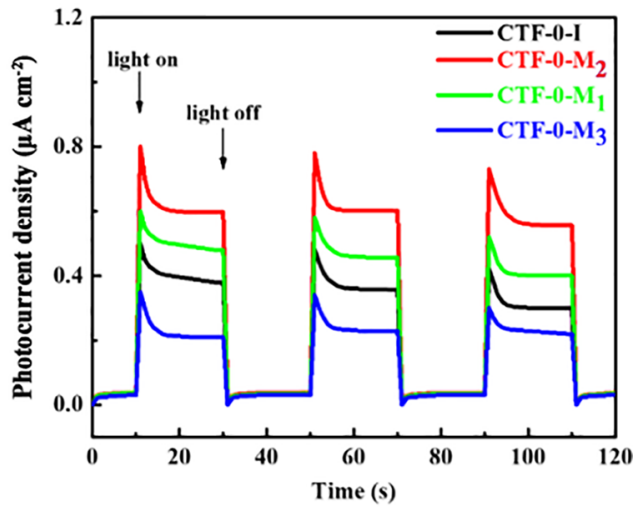

(e)

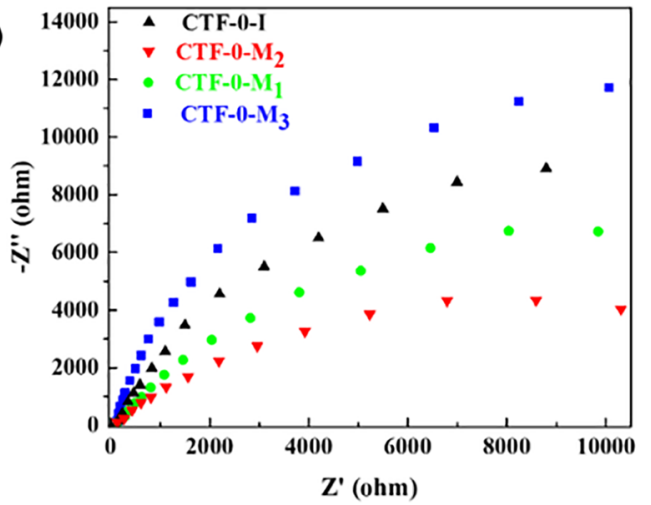

Figure 5. Spatial distribution of the conduction band minimum (CBM) (a) and valence band maximum (VBM) (c). Isosurface was set to $0.01 e$ / $r_{0}{ }^{3}$, where $r_{0}$ is the Bohr radii. Solid lines represent the primary cell of the CTF-0. Band alignments (b) of CTF-0 estimated by DFT calculations. All energies were calculated with reference to the vacuum level. Brown, purple, and pale pink spheres represent carbon, nitrogen, and hydrogen atoms,

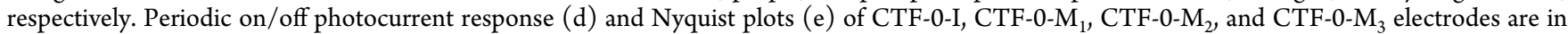
$0.1 \mathrm{M} \mathrm{Na}_{2} \mathrm{SO}_{4}$ with $0 \mathrm{~V}$ bias versus $\mathrm{Ag} / \mathrm{AgCl}$.

hydrogen evolution reaction was conducted in the presence of $3 \mathrm{wt} \% \mathrm{Pt}$ as the cocatalyst and triethanolamine (TEOA) as the sacrificial electron donor. It is noted that the $\mathrm{H}_{2}$ evolution rate measured here on CTF- $-\mathrm{M}_{2}$ is the highest among all of the polymers, up to $7010 \mu \mathrm{mol} \mathrm{h}{ }^{-1} \mathrm{~g}^{-1}$ as shown in Figure 3a, which is six times higher than the activity of CTF-0-M $\mathrm{M}_{3}$ of 1160 $\mu \mathrm{mol} \mathrm{h}{ }^{-1} \mathrm{~g}^{-1}$. CTF-0-M $\mathrm{M}_{2}$ is also very active under visible-light irradiation, reaching $1030 \mu \mathrm{mol} \mathrm{h}^{-1} \mathrm{~g}^{-1}$ as shown in Figure $3 \mathrm{c}$, which is around seven times more than CTF-0-M 3 at $150 \mu \mathrm{mol}$ $\mathrm{h}^{-1} \mathrm{~g}^{-1}$. The turnover number of CTF-0-M $\mathrm{M}_{2}$ in terms of reacted electrons relative to the amount of Pt reaches 726 after a 6-h running experiment. Furthermore, the oxygen evolution reaction over these materials without any cocatalyst was carried out in the presence of $\mathrm{Ag}^{+}$as the electron scavenger. CTF-0-I shows the highest activity for $\mathrm{O}_{2}$ evolution under both full arc and visible-light irradiation (226 and $59 \mu \mathrm{mol} \mathrm{g}^{-1}$ in the first hour, respectively) as shown in Figure $3 \mathrm{~b}$ and $3 \mathrm{~d}$.

The photocatalytic activity for water reduction and oxidation correlates well to the band positions as shown in Figure $4 \mathrm{a}$ and $4 \mathrm{~b}$. The deeper the valence band edge, the higher the water oxidation rate, and similarly the more negative the conduction band edge, the higher the water reduction rate. The relatively large surface area of $201 \mathrm{~m}^{2} \mathrm{~g}^{-1}$ for CTF-0-I versus $5 \mathrm{~m}^{2} \mathrm{~g}^{-1}$ for CTF-0-Ms also favors the photocatalytic efficiency by providing a greater number of active sites, while there is no oxygen generated on CTF- $0-\mathrm{M}_{2}$ under the same reaction conditions due to the more negative valence band edge than required for the water oxidation reaction.
To further prove that the reaction is driven by light absorption, the apparent quantum yield (AQY) for $\mathrm{H}_{2}$ generation over 3 wt $\%$ Pt/CTF-0-M $\mathrm{M}_{2}$ was examined with band-pass filters at different wavelengths. The AQY is $11 \%$ at $365 \mathrm{~nm}$ and $8 \%$ at $420 \mathrm{~nm}$. Notably, $\mathrm{H}_{2}$ can also be produced even at $600 \mathrm{~nm}$ and results in an AQY of $0.6 \%$ as shown in Figure 4c. Figure $4 d$ presents the hydrogen evolution rate during seven day-long runs. There is no noticeable deactivation in $\mathrm{H}_{2}$ evolution over CTF- $0-\mathrm{M}_{2}$ as shown in Figure $4 \mathrm{~d}$, and around $4900 \mu \mathrm{mol}$ of $\mathrm{H}_{2}$ was produced in total during these seven cycles, leading to a high turnover number (TON) of 726 over platinum cocatalysts. The XRD patterns and FTIR spectra of CTF- $0-\mathrm{M}_{2}$ after $50 \mathrm{~h}$ are similar to those of the fresh sample as shown in Figure S11, indicating that the chemical structure is stable during photocatalytic reactions. On the other hand, the AQY for $\mathrm{O}_{2}$ evolution over CTF-0-I is observed to be $15 \%$ $(365 \mathrm{~nm})$ and $5.2 \%(420 \mathrm{~nm})$ as shown in Figure S12a. Figure $\mathrm{S} 12 \mathrm{~b}$ illustrates that CTF-0-I is able to produce $\mathrm{O}_{2}$ continuously over $39 \mathrm{~h}$ and obtains $305.9 \mu \mathrm{mol}$ in total without any cocatalyst. It should also be noted that $\mathrm{N}_{2}$ evolution could not be detected during the reaction as shown in Figure S12b, indicating all of the oxygen generated is from the photocatalytic water splitting, not from air leaks. The rate of $\mathrm{O}_{2}$ evolution decreases during the reaction because of the deposition of metallic silver on the surface of CTF-0-I, shielding the incident light and turning the sample black. There is no noticeable difference in the XRD and FTIR spectra of the sample before and after oxygen evolution reactions as 
shown in Figure S13, except for a diffraction at ca. $38^{\circ}$ after the reaction in the XRD pattern (Figure S13a) attributed to metallic Ag. The XPS spectra of CTF-0-I before and after the reaction (Figure S14) are also consistent with the observation of $\mathrm{Ag}$ deposition generated by the $\mathrm{Ag}^{+}$reduction, which is a typical behavior in the photocatalytic water oxidation reaction when $\mathrm{Ag}^{+}$is used as the electron scavenger. ${ }^{40-42}$ These results indicate the excellent stability of both CTF-0-M 2 and CTF-0-I for photocatalytic proton reduction and water oxidation, respectively. It is interesting to see that the covalent triazinebased framework CTF-0-M $\mathrm{M}_{2}$ produced by microwave shows higher rates of photocatalytic hydrogen evolution under both $\mathrm{UV}$ and visible-light irradiation than the previously reported CTF-1, leading to an AQY of $2 \%$ even at $500 \mathrm{~nm}, 3$ times higher than CTF-1 under identical experimental conditions. ${ }^{34}$ In parallel, CTF-0-I exhibits the best photocatalytic water oxidation performance without any cocatalysts, resulting in $5.2 \%$ AQY at $420 \mathrm{~nm}$, again 5 times higher than CTF-1 under the same experimental conditions. ${ }^{34}$

To further understand the electronic properties at the atomic level, the monolayer CTF-0 was investigated by DFT calculations. Detailed settings are illustrated in the Experimental Section. As shown in the Figure 5a, the charge in the conduction band minimum (CBM) of the monolayer CTF-0 contains a major contribution from the triazine units and the carbon bonded to hydrogen in the benzene units. The notable electrons only from $\mathrm{p}_{z}$ orbitals preferentially determine the CBM. The valence band maximum (VBM), as shown in Figure $5 \mathrm{c}$, is only located over the triazine donors and contains contributions from electrons in the $\mathrm{p}_{x}$ and $\mathrm{p}_{y}$ orbitals of the nitrogen atoms. The energy level diagram of the monolayer CTF-0 is shown in Figure $5 \mathrm{~b}$. The simulated CBM and VBM of CTF-0 lie at -3.65 and $-6.22 \mathrm{eV}$ (vs vacuum), respectively. Compared with the redox potential of water reduction $(-4.44$ $\mathrm{eV}$ vs vacuum) and oxidation ( $-5.67 \mathrm{eV}$ vs vacuum), the CBM and VBM provide sufficient driving force for both hydrogen and oxygen generation, respectively. According to Table S1, the nitrogen to carbon ratios are $0.36,0.35,0.34$, and 0.26 for

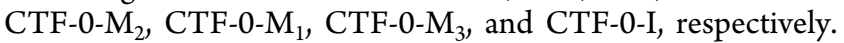
Hence, we speculate that the proposed VBM in Figure $2 \mathrm{~d}$ shifts down with the decrease in triazine units, leading to the positions of VBM following the order of CTF-0-M $2<$ CTF-0$\mathrm{M}_{1}<$ CTF-0-M $\mathrm{M}_{3}<$ CTF-0-I and CTF-0-I has the largest band gap based on the smaller change of the CBM. Meanwhile, as shown in Figure S2, different stacking will also tune the position of the CBM. Our calculations based on trilayer AAand $\mathrm{AB}$-stacking orientations show that compared with $\mathrm{AB}$ stacking, the AA stacking lowers the CBM by $0.15 \mathrm{eV}$, which is consistent with the experimental results of CTF-0-I (AA stacking) that presents a lower band gap edge position than CTF-0-M $\mathrm{M}_{2}$ (AB stacking). However, the calculated VBM is not impacted by the stacking. Thus, the main contribution of the VBM shift is likely due to the nitrogen to carbon ratio. At the same time, the decrease of nitrogen content results in significant widening of the band gap, and thus, the material to some extent retains the capability to reduce water into $\mathrm{H}_{2}$.

One can see that although the ratio of triazine rings to benzene rings well interprets the VBM shift, the terminal nitrile group to benzene rings is quite high (Table S3 and Figure 1c) and the nitrile contribution could not be ignored. Further calculations with $-\mathrm{CN}$ residue were carried out based on a $2 \times$ 2 supercell with extracting one 1,3,5-tricyanobenzene group to represent the material with unreacted $-\mathrm{CN}$ group, as shown in
Figure S15. The unsaturated carbon atoms were saturated by $\mathrm{H}$. Three different nitrogens in the framework were denoted as nitrile, triazine, and link nitrogen. The projected density of states (pDOS) were plotted in Figure S16a. For the nitrilecontaining CTF- 0 , the $\mathrm{p}_{z}$ orbitals of the $\mathrm{N}$ in the nitrile group and the link contribute to the VBM and CBM, respectively. The change is also reflected in the band alignments, plotted in Figure S16b. Compared with monolayer pristine CTF-0, the nitrile-containing frameworks have a lower band offset of the CBM. Considering the real system consists of both pristine CTF-0 and CTF-0 with a nitrile group, the nitrile groups will further narrow the band gap, resulting into a band gap with the order CTF-0-M $\mathrm{M}_{2}<$ CTF-0-M $\mathrm{M}_{1}<$ CTF-0-M .

To uncover the kinetics of photocatalysis in the CTF-0s, photocurrent responses and electrochemical impedance spectroscopy (EIS) were conducted over CTF-0-I-, CTF-0-M $1^{-}$, CTF-0-M $\mathrm{M}_{2}$, and CTF-0-M $\mathrm{M}_{3}$-coated electrodes in a threeelectrode photoelectrochemical system. Figure $5 \mathrm{~d}$ shows the photocurrent curve generated by the electrodes for several onoff cycles of irradiation. The photocurrent goes down to zero rapidly once the light turns off, while the photocurrent will return to a steady value when the light turns on again. The CTF-0- $\mathrm{M}_{2}$-coated photoelectrode shows the highest photocurrent over the other photoelectrodes, indicating the highest efficiency for suppressing charge recombination likely owing to the improvement of interlayer charge transfer indicated by the PL spectra in Figure 2a. The current density follows the order CTF-0-M $\mathrm{M}_{2}>$ CTF-0-M $>$ CTF-0-I > CTF-0-M $\mathrm{M}_{3}$, which is in good agreement with the photocatalytic performance for hydrogen generation. The charge transfer resistance was investigated by EIS. Figure 5e reveals that the Nyquist plot arc radius of CTF- $0-\mathrm{M}_{2}$ is much smaller than other samples, suggesting lower electric charge transfer resistance and faster interlayer photoinduced electron transfer. This trend is consistent with the photocurrent results. Above all, the CTF$0-\mathrm{M}_{2}$ showed the highest photocatalytic activity for proton reduction among all samples, probably because of the narrowest band gap and most negative CBM as well as the most efficient transport of photoinduced electrons in the ordered-interlayer structure. These interesting results from two complementary polymers point to a potential Z-scheme for effective water splitting, which is currently underway.

\section{CONCLUSIONS}

In summary, we present here polymeric covalent triazine-based frameworks as tunable nonmetal photocatalysts synthesized by microwave and ionothermal methods. The triazine units can be controlled by the precursor concentration and the preparation method. A higher amount of nitrogen or triazine units results in a more negative valence band edge, or the higher the amount of benzene units, the more positive the valence band position, as confirmed by XPS and modeling, indicating the triazine unit dominates the valence band positions. The covalent triazine-based framework CTF- $0-\mathrm{M}_{2}$ produced by the microwave method with the most ordered interlayer structure and the highest amount of triazine units shows the best photocatalytic hydrogen evolution under both UV and visiblelight irradiation, resulting in ca. 8\% AQY at $420 \mathrm{~nm}$ and $2 \%$ at $500 \mathrm{~nm}$. The superior performance is ascribed to the narrowest band gap, efficient interlayer charge transfer, and a more negative conduction band edge than others. CTF-0-I with the highest benzene to triazine ratio exhibits the best photocatalytic water oxidation performance under both full arc and 
visible-light irradiation, leading to $5.2 \% \mathrm{AQY}$ at $420 \mathrm{~nm}$, which is due to the deepest valence band edge and the relatively large surface area. Thus, both efficient half-reaction photocatalysts have been obtained. These triazine moieties can in principle be readily tuned to further study their applications in overall water splitting using a Z-scheme pathway and to explore the mechanism of water oxidation and reduction to enhance their light harvesting capability. The development of CTFs as tunable frameworks for photocatalytic hydrogen and oxygen evolution promotes the design of tailor-made photosensitizers and photocatalysts with tunable optical and electronical properties, which can also open a new avenue to diversify the ongoing development of CTFs for optoelectronic applications.

\section{EXPERIMENTAL SECTION}

4.1. Chemicals. All chemicals were used as received: $1,3,5-$ tricyanobenzene (OTAVA Ltd.); trifluoromethanesulfonic acid >99\% (TFMS) (Sigma-Aldrich); zinc chloride 99.99\% (Alfa Aesar).

4.2. Synthesis of CTF-0-I. CTF-0-I was synthesized from 1 $\mathrm{g}(6.5 \mathrm{mmol})$ of 1, 3, 5-tricyanobenzene and using $0.9 \mathrm{~g}(6.5$ mmol) of $\mathrm{ZnCl}_{2}$ as a catalyst in a glass ampule. The ampule was dried under vacuum at $100{ }^{\circ} \mathrm{C}$ for $12 \mathrm{~h}$. The ampule was then flame sealed and transferred into a furnace for heat treatment at $400{ }^{\circ} \mathrm{C}$ for $40 \mathrm{~h}$. Breaking the cool ampule yielded a light-yellow solid which was then ground thoroughly. The powder was dispersed in water and kept stirring for $12 \mathrm{~h}$ at 90 ${ }^{\circ} \mathrm{C}$ after sonication. $\mathrm{HCl}(0.1 \mathrm{M})$ was added, and the solution was stirred for another $12 \mathrm{~h}$ at $90{ }^{\circ} \mathrm{C}$. The sample was finally washed successively with water, acetone, and ethanol and then dried in a vacuum oven at $120^{\circ} \mathrm{C}$ for $12 \mathrm{~h}$.

4.3. Synthesis of CTF-0-Ms. CTF-0-M $\mathrm{M}_{1}, \mathrm{CTF}-0-\mathrm{M}_{2}$, and CTF-0- $\mathrm{M}_{3}$ were synthesized with $1 \mathrm{~g}$ of 1,3,5-tricyanobenzene $(6.5 \mathrm{mmol})$ and $1.5,2$, and $2.5 \mathrm{~mL}(17,23$, and $28 \mathrm{mmol})$ of TFMS as a catalyst and solvent. First, $1 \mathrm{~g}$ of 1,3,5tricyanobenzene powder was moved into a $10 \mathrm{~mL}$ glass reaction vessel (CEM, Discover and Explorer SP Vessels) ${ }^{34}$ with a magnetic stirrer. Under the ambient atmosphere, the vessel was covered by a pressure control cap. The reaction was conducted under a dynamic mode with a controlled temperature of $110{ }^{\circ} \mathrm{C}$, and the reaction time was $30 \mathrm{~min}$. The maximum power of the microwave was set at $300 \mathrm{~W}$ and the safety pressure was set at $300 \mathrm{psi}$. In the first minute, the solution started boiling and pale-yellow solid precipitates were formed gradually. After $30 \mathrm{~min}$ of microwave heating the precipitates were collected and washed by ammonia solution to remove the acid and then washed with ethanol, acetone, and water. Finally, the products were obtained as powders after drying in a vacuum oven at $180{ }^{\circ} \mathrm{C}$ for $12 \mathrm{~h}$.

4.4. Characterization. Powder X-ray diffraction patterns (PXRD) of the as-prepared samples were taken by a Bruker D4 diffractometer with Ni-filtered $\mathrm{Cu} \mathrm{K} \alpha$ irradiation $\left(\lambda_{1}=\right.$ $\left.1.540562 \AA, \lambda_{2}=1.544398 \AA\right)$. The Brunauer-EmmettTeller (BET) surface area measurement was performed on a Quantachrome Autosorb-iQC with $\mathrm{Ar}$ as a carrier gas at $87 \mathrm{~K}$. Solid-state nuclear magnetic resonance (ssNMR) spectra were carried out on a Bruker Advance 300WB spectrometer running with a $4 \mathrm{~mm}$ magic-angle spinning probe for ${ }^{13} \mathrm{C}$ and ${ }^{1} \mathrm{H}$ measurements. Fourier transform infrared spectra (FTIR) were performed on a PerkinElmer 1605 FT-IR spectrometer in the wavelength range from 400 to $4000 \mathrm{~cm}^{-1}$ with a resolution of $0.5 \mathrm{~cm}^{-1}$. UV-vis reflectance spectroscopy was conducted using a Shimazu UV-vis 2550 spectrophotometer fitted with barium sulfate as a reference. Photoluminescence (PL) spectroscopy measurements were performed on a Renishaw spectrograph system based on use of Kayser notch filters with a sensitive CCD detector coupled to a microscope for point-bypoint analyses using a $325 \mathrm{~nm}$ excitation laser and a wavenumber range of $100-2000 \mathrm{~cm}^{-1}$. X-ray photoelectron spectra (XPS) were performed using a Thermoscientific XPS $\mathrm{K}$-alpha surface analysis machine using an $\mathrm{Al}$ source. Analysis was performed using CasaXPS. Time-resolved PL spectra were obtained on a TCSPC (LifeSpec-ps) from Edinburgh Instruments with an excitation wavelength of $405 \mathrm{~nm}$ at $-15{ }^{\circ} \mathrm{C}$ and fitted with a multi-exponential function with three decay components using Origin.

4.5. Theoretical Calculations. To understand the electron properties of the investigated compounds CTF-0, theoretical calculations based on density functional theory (DFT) were performed, which was implanted in the Vienna ab initio Package (VASP). ${ }^{44}$ A plane wave cutoff of $520 \mathrm{eV}$ was selected, with the projector augmented wave methods used to treat the core electrons. ${ }^{45}$ The PBE functional was used for structure optimization and electronic structure analysis. ${ }^{46}$ van der Waals interactions were included via usage of the DFT-D2 method of Grimme. ${ }^{47}$ All atoms were fully relaxed until the change in force upon ionic displacement was less than 0.01 $\mathrm{eV} / \AA$, with the change in energies no greater than $10^{-5} \mathrm{eV}$. The bulk CTF-0 was generated using the AA- and AB-stacking motif. The electronic properties were studied based on monolayer CTF-0. A Monkhorst-Pack $k$-point mesh of $11 \times$ $11 \times 1$ was found to be sufficient in order to produce wellconverged energies and forces. Spin polarization was used in all calculations. As a large vacuum spacing (15 $\AA$ ) was used in our simulations, the planar averaged electrostatic potential converged to a constant value far from the surface. These converged values may be taken as the reference level with which the Kohn-Sham (KS) eigenvalues are aligned. ${ }^{48}$ For the band alignment of the CTF-0, the Fermi level was determined by the calculations of each work function, where the vacuum is set to zero. For the study of the defected CTF-0 with nitrile terminals, a $2 \times 2$ supercell with one with distracting one $1,3,5$ tricyanobenzene group to represent the material with an unsaturated $-\mathrm{CN}$ group in experiments (Figure S15). A $\mathrm{K}$ point sampling was set to $5 \times 5 \times 1$ for the supercell calculations.

4.6. Photocatalytic Measurements. Oxygen and hydrogen evolution performance was carried out separately in a custom Pyrex batch reactor cell under the irradiation of a 300 W Xe lamp (TrusTech PLS-SXE 300/300UV). A reaction cell under full-arc irradiation was used for hydrogen evolution, containing $100 \mathrm{mg}$ of solid catalysts loaded with $3 \mathrm{wt} \% \mathrm{Pt}$ and $230 \mathrm{~mL}$ of $\mathrm{H}_{2} \mathrm{O}$ mixed with $10 \mathrm{vol} \%$ triethanolamine. For the oxygen evolution reaction, the reactor contained $100 \mathrm{mg}$ of solid catalysts and $1 \mathrm{~g}$ of $\mathrm{AgNO}_{3}$ dissolved in $230 \mathrm{~mL}$ of $\mathrm{H}_{2} \mathrm{O}$. Before the reaction, the reactor was sealed and then purged with argon to remove air. To measure the photocatalytic efficiency under visible-light irradiation, a $420 \mathrm{~nm}$ long pass filter was installed in front of the lamp to remove UV light. Bandpass light filters, 365, 420, 500, 600, and $800 \mathrm{~nm}$, were used for quantum efficiency measurements. All of the product gas was analyzed by gas chromatography (Varian 430-GC, TCD, argon carrier gas 99.999\%). The apparent quantum efficiency $(\Phi)$ was calculated by the equation 


$$
\Phi=(N \times O / n) \times 100
$$

where $N, O$, and $n$ are the number of charge carriers for one mole of gas, moles of gas evolved, and number of the incident photons, respectively. The number of incident photons was calculated by the equation $n=I /(h c / \lambda)=I \lambda / h c$, where the light intensity $I$ was measured by a Newport power meter. Detailed parameters for calculating the AQY data are shown in Table S4. The turnover number (TON) was calculated after seven cycles by using the following formula: TON $=$ moles of $\mathrm{H}_{2}$ molecules generated/mole of active sites (herein platinum amount on the surface of the photocatalyst).

4.7. Photoelectrochemical Measurements. The photoelectrochemical properties were investigated in a conventional three-electrode cell using an electrochemical analyzer (IVIUM Technologies). ${ }^{49}$ CTF-0 films were prepared as follows: FTO glass was washed sequentially with distilled water, ethanol, and acetone in an ultrasonic cleaner for $30 \mathrm{~min}$. Then $5 \mathrm{mg}$ CTF-0 powder was mixed with $750 \mu \mathrm{L}$ of distilled water, $250 \mu \mathrm{L}$ of 2 propanol, and $10 \mu \mathrm{L}$ of Nafion in an ultrasonic cleaner for 30 min, and then the slurry was coated onto $2 \mathrm{~cm} \times 2 \mathrm{~cm}$ FTO by drop casting. After drying overnight on a hot plate at $250^{\circ} \mathrm{C}$, the electrodes were sintered at $400{ }^{\circ} \mathrm{C}$ for $30 \mathrm{~min}$ to improve adhesion. The prepared films, a Pt mesh, and $\mathrm{Ag} / \mathrm{AgCl}$ (saturated $\mathrm{KCl}$ ) were used as the working, counter, and reference electrodes, respectively. Sunlight was simulated with a $150 \mathrm{~W}$ xenon lamp (Newport) and AM 1.5 filter (Newport). The light intensity was tuned using a calibrated crystalline silicon solar cell, equivalent to global AM 1.5 illumination at $100 \mathrm{~mW} / \mathrm{cm}^{2}$. The photocurrent of the samples was measured in $0.1 \mathrm{M} \mathrm{Na}_{2} \mathrm{SO}_{4}$ aqueous solution $(\mathrm{pH}=6.5)$. Samples were illuminated from the back side (FTO substrate side), and the masked-off irradiated area was $0.5 \mathrm{~cm}^{2}$. Mott-Schottky curves were measured at a certain $\mathrm{dc}$ potential range with an ac amplitude of $5 \mathrm{mV}$ and frequencies of $0.5,1$, and $2 \mathrm{kHz}$ under dark conditions. Electrochemical impedance spectra (EIS) were measured with $0.0 \mathrm{~V}$ bias versus $\mathrm{AgCl} / \mathrm{Ag}$.

\section{ASSOCIATED CONTENT}

\section{S Supporting Information}

The Supporting Information is available free of charge on the ACS Publications website at DOI: 10.1021/acscatal.9b02195.

Supplementary characterization and activation calculation results (PDF)

\section{AUTHOR INFORMATION}

\section{Corresponding Authors}

*E-mail: bzm@buaa.edu.cn.

*E-mail: z.x.guo@ucl.ac.uk.

*E-mail: junwang.tang@ucl.ac.uk.

ORCID

Jijia Xie: 0000-0003-4609-8915

Zhengxiao Guo: 0000-0001-5404-3215

Junwang Tang: 0000-0002-2323-5510

\section{Present Address}

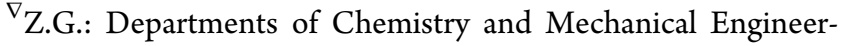
ing, the University of Hong Kong, Hong Kong.

\section{Author Contributions}

D.K. conducted the preparation and characterization of the polymeric materials and photocatalytic performance tests as well as writing the paper. X.H. undertook the theoretical modeling. J.X. contributed to surface area measurement and discussion of other physical characterizations. Q.R. carried out the PEC tests and results analysis. K.S. carried out the timeresolved photoluminescence (TRPL) performance. S.G. helped prepare the polymeric materials and carried out measurments of isothermal adsorptions. C.W. discussed the materials synthesis methods and band structure. Z.B. contributed to the band positions measurement and discussion. Z.X.G. supervised the modeling work. J.T. initiated and entirely supervised this project. Z.X.G. and J.T. both discussed the fundamentals of this work and finalized the paper. All authors have given approval to the final version of the manuscript.

Notes

The authors declare no competing financial interest.

\section{ACKNOWLEDGMENTS}

All authors thank Dr. Chiching Lau, Dr. Yaomin Li and Tina Miao at UCL for the BET, UV-vis spectra and TRPL discussions. D. K, J.X, Q.R, C.W, Z.B., and J.T. are thankful for the financial support from UK EPSRC (EP/N009533/1), Royal Society-Newton Advanced Fellowship grant (NA170422), and the Leverhulme Trust (RPG-2017-122). D.K. and Q.R. are grateful for the financial support by the UCL Engineering Dean's Prize and the Chinese Scholarship Council (CSC) for Ph.D. studentships. X.H. and X.G. acknowledge financial support from UK EPSRC (EP/N032888/1, EP/ L018330/1, EP/K021192/1) and use of the UCL Grace High Performance Computing Facility (Grace@UCL), and associated support services, in the completion of this work.

\section{REFERENCES}

(1) Chi, J.; Yu, H. Water Electrolysis Based on Renewable Energy for Hydrogen Production. Cuihua Xuebao/Chin. J. Catal. 2018, 39 (3), 390-394.

(2) Wang, Y.; Bayazit, M. K.; Moniz, S. J. A. A.; Ruan, Q.; Lau, C. C.; Martsinovich, N.; Tang, J. Linker-Controlled Polymeric Photocatalyst for Highly Efficient Hydrogen Evolution from Water. Energy Environ. Sci. 2017, 10 (7), 1643-1651.

(3) Kong, D.; Zheng, Y.; Kobielusz, M.; Wang, Y.; Bai, Z.; Macyk, W.; Wang, X.; Tang, J. Recent Advances in Visible Light-Driven Water Oxidation and Reduction in Suspension Systems. Mater. Today 2018, 21 (8), 897-924.

(4) Maeda, K.; Teramura, K.; Lu, D.; Takata, T.; Saito, N.; Inoue, Y.; Domen, K. Photocatalyst Releasing Hydrogen from Water. Nature 2006, 440 (7082), 295-295.

(5) Wang, Q.; Hisatomi, T.; Jia, Q.; Tokudome, H.; Zhong, M.; Wang, C.; Pan, Z.; Takata, T.; Nakabayashi, M.; Shibata, N.; Li, Y.; Sharp, I. D.; Kudo, A.; Yamada, T.; Domen, K. Scalable Water Splitting on Particulate Photocatalyst Sheets with a Solar-toHydrogen Energy Conversion Efficiency Exceeding 1\%. Nat. Mater. 2016, 15 (6), 611-615.

(6) Wang, Y.; Suzuki, H.; Xie, J.; Tomita, O.; Martin, D. J.; Higashi, M.; Kong, D.; Abe, R.; Tang, J. Mimicking Natural Photosynthesis: Solar to Renewable H2 Fuel Synthesis by Z-Scheme Water Splitting Systems. Chem. Rev. 2018, 118 (10), 5201-5241.

(7) Chen, S.; Takata, T.; Domen, K. Particulate Photocatalysts for Overall Water Splitting. Nat. Rev. Mater. 2017, 2, 17050.

(8) Chowdhury, F. A.; Trudeau, M. L.; Guo, H.; Mi, Z. A Photochemical Diode Artificial Photosynthesis System for Unassisted High Efficiency Overall Pure Water Splitting. Nat. Commun. 2018, 9 (1), 1707.

(9) Ni, M.; Leung, M. K. H.; Leung, D. Y. C.; Sumathy, K. A Review and Recent Developments in Photocatalytic Water-Splitting Using TiO 2 for Hydrogen Production. Renewable Sustainable Energy Rev. 2007, 11 (3), 401-425. 
(10) Khan, S. U. M.; Al-Shahry, M.; Ingler, W. B. Efficient Photochemical Water Splitting by a Chemically Modified N-TiO2. Science 2002, 297 (5590), 2243-2245.

(11) Maeda, K.; Takata, T.; Hara, M.; Saito, N.; Inoue, Y.; Kobayashi, H.; Domen, K. GaN:ZnO Solid Solution as a Photocatalyst for Visible-Light-Driven Overall Water Splitting. J. Am. Chem. Soc. 2005, 127 (23), 8286-8287.

(12) Yang, X.; Wolcott, A.; Wang, G.; Sobo, A.; Fitzmorris, R. C.; Qian, F.; Zhang, J. Z.; Li, Y. Nitrogen-Doped ZnO Nanowire Arrays for Photoelectrochemical Water Splitting. Nano Lett. 2009, 9 (6), 2331-2336.

(13) Wen, J.; Li, X.; Liu, W.; Fang, Y.; Xie, J.; Xu, Y. Photocatalysis Fundamentals and Surface Modification of $\mathrm{TiO} 2$ Nanomaterials. Cuihua Xuebao/Chin. J. Catal. 2015, 36 (12), 2049-2070.

(14) Ong, W. J.; Tan, L. L.; Ng, Y. H.; Yong, S. T.; Chai, S. P. Graphitic Carbon Nitride (g-C3N4)-Based Photocatalysts for Artificial Photosynthesis and Environmental Remediation: Are We a Step Closer to Achieving Sustainability? Chem. Rev. 2016, 116 (12), 7159-7329.

(15) Zuo, F.; Wang, L.; Wu, T.; Zhang, Z.; Borchardt, D.; Feng, P. Self-Doped Ti3+ Enhanced Photocatalyst for Hydrogen Production under Visible Light. J. Am. Chem. Soc. 2010, 132 (34), 11856-11857.

(16) Asahi, R.; Morikawa, T.; Ohwaki, T.; Aoki, K.; Taga, Y. VisibleLight Photocatalysis in Nitrogen-Doped Titanium Oxides. Science 2001, 293 (5528), 269-271.

(17) Li, X.; Kikugawa, N.; Ye, J. Nitrogen-Doped Lamellar Niobic Acid with Visible Light-Responsive Photocatalytic Activity. Adv. Mater. 2008, 20 (20), 3816-3819.

(18) Wang, X.; Maeda, K.; Thomas, A.; Takanabe, K.; Xin, G.; Carlsson, J. M.; Domen, K.; Antonietti, M. A Metal-Free Polymeric Photocatalyst for Hydrogen Production from Water under Visible Light. Nat. Mater. 2009, 8 (1), 76-80.

(19) Yang, S.; Gong, Y.; Zhang, J.; Zhan, L.; Ma, L.; Fang, Z.; Vajtai, R.; Wang, X.; Ajayan, P. M. Exfoliated Graphitic Carbon Nitride Nanosheets as Efficient Catalysts for Hydrogen Evolution under Visible Light. Adv. Mater. 2013, 25 (17), 2452-2456.

(20) Zhang, G.; Lan, Z.-A.; Wang, X. Conjugated Polymers: Catalysts for Photocatalytic Hydrogen Evolution. Angew. Chem., Int. Ed. 2016, 55 (51), 15712-15727.

(21) Wang, Y.; Silveri, F.; Bayazit, M. K.; Ruan, Q.; Li, Y.; Xie, J.; Catlow, C. R. A.; Tang, J. Bandgap Engineering of Organic Semiconductors for Highly Efficient Photocatalytic Water Splitting. Adv. Energy Mater. 2018, 8 (24), 1801084.

(22) Liu, J.; Liu, Y.; Liu, N.; Han, Y.; Zhang, X.; Huang, H.; Lifshitz, Y.; Lee, S. T.; Zhong, J.; Kang, Z. Metal-Free Efficient Photocatalyst for Stable Visible Water Splitting via a Two-Electron Pathway. Science 2015, 347 (6225), 970-974.

(23) Jiang, W.; Ruan, Q.; Xie, J.; Chen, X.; Zhu, Y.; Tang, J. OxygenDoped Carbon Nitride Aerogel: A Self-Supported Photocatalyst for Solar-to-Chemical Energy Conversion. Appl. Catal., B 2018, 236, $428-435$.

(24) Schwinghammer, K.; Tuffy, B.; Mesch, M. B.; Wirnhier, E.; Martineau, C.; Taulelle, F.; Schnick, W.; Senker, J.; Lotsch, B. V. Triazine-based Carbon Nitrides for Visible-Light-Driven Hydrogen Evolution. Angew. Chem., Int. Ed. 2013, 52 (9), 2435-2439.

(25) Sprick, R. S.; Jiang, J. X.; Bonillo, B.; Ren, S.; Ratvijitvech, T.; Guiglion, P.; Zwijnenburg, M. A.; Adams, D. J.; Cooper, A. I. Tunable Organic Photocatalysts for Visible-Light-Driven Hydrogen Evolution. J. Am. Chem. Soc. 2015, 137 (9), 3265-3270.

(26) Vyas, V. S.; Haase, F.; Stegbauer, L.; Savasci, G.; Podjaski, F.; Ochsenfeld, C.; Lotsch, B. V. A Tunable Azine Covalent Organic Framework Platform for Visible Light-Induced Hydrogen Generation. Nat. Commun. 2015, 6, 8508.

(27) Bi, J.; Fang, W.; Li, L.; Wang, J.; Liang, S.; He, Y.; Liu, M.; Wu, L. Covalent Triazine-Based Frameworks as Visible Light Photocatalysts for the Splitting of Water. Macromol. Rapid Commun. 2015, 36 (20), 1799-1805.
(28) Schwinghammer, K.; Hug, S.; Mesch, M. B.; Senker, J.; Lotsch, B. V. Phenyl-Triazine Oligomers for Light-Driven Hydrogen Evolution. Energy Environ. Sci. 2015, 8 (11), 3345-3353.

(29) Huang, W.; He, Q.; Hu, Y.; Li, Y. Molecular Heterostructures of Covalent Triazine Frameworks for Enhanced Photocatalytic Hydrogen Production. Angew. Chem., Int. Ed. 2019, 58, 8676-8680.

(30) Kuhn, P.; Antonietti, M.; Thomas, A. Porous, Covalent Triazine-Based Frameworks Prepared by Ionothermal Synthesis. Angew. Chem., Int. Ed. 2008, 47 (18), 3450-3453.

(31) Katekomol, P.; Roeser, J.; Bojdys, M.; Weber, J.; Thomas, A. Covalent Triazine Frameworks Prepared from 1,3,5-Tricyanobenzene. Chem. Mater. 2013, 25 (9), 1542-1548.

(32) Bojdys, M. J.; Jeromenok, J.; Thomas, A.; Antonietti, M. Rational Extension of the Family of Layered, Covalent, TriazineBased Frameworks with Regular Porosity. Adv. Mater. 2010, 22 (19), 2202-2205.

(33) Ren, S.; Bojdys, M. J.; Dawson, R.; Laybourn, A.; Khimyak, Y. Z.; Adams, D. J.; Cooper, A. I. Porous, Fluorescent, Covalent Triazine-Based Frameworks via Room-Temperature and MicrowaveAssisted Synthesis. Adv. Mater. 2012, 24 (17), 2357-2361.

(34) Xie, J.; Shevlin, S. A.; Ruan, Q.; Moniz, S. J. A.; Liu, Y.; Liu, X.; Li, Y.; Lau, C. C.; Guo, Z. X.; Tang, J. Efficient Visible Light-Driven Water Oxidation and Proton Reduction by an Ordered Covalent Triazine-Based Framework. Energy Environ. Sci. 2018, 11 (6), 16171624.

(35) Jiang, X.; Wang, P.; Zhao, J. 2D Covalent Triazine Framework: A New Class of Organic Photocatalyst for Water Splitting. J. Mater. Chem. A 2015, 3 (15), 7750-7758.

(36) Wang, X.; Chen, L.; Chong, S. Y.; Little, M. A.; Wu, Y.; Zhu, W. H.; Clowes, R.; Yan, Y.; Zwijnenburg, M. A.; Sprick, R. S.; Cooper, A. I. Sulfone-Containing Covalent Organic Frameworks for Photocatalytic Hydrogen Evolution from Water. Nat. Chem. 2018, 10 (12), $1180-1189$

(37) Liu, J.; Lyu, P.; Zhang, Y.; Nachtigall, P.; Xu, Y. New Layered Triazine Framework/Exfoliated 2D Polymer with Superior SodiumStorage Properties. Adv. Mater. 2018, 30 (11), 1705401.

(38) Bégué, D.; Qiao, G. G.; Wentrup, C. Nitrile Imines: Matrix Isolation, IR Spectra, Structures, and Rearrangement to Carbodiimides. J. Am. Chem. Soc. 2012, 134 (11), 5339-5350.

(39) Xie, J.; Jin, R.; Li, A.; Bi, Y.; Ruan, Q.; Deng, Y.; Zhang, Y.; Yao, S.; Sankar, G.; Ma, D.; Tang, J. Highly Selective Oxidation of Methane to Methanol at Ambient Conditions by Titanium DioxideSupported Iron Species. Nat. Catal. 2018, 1 (11), 889-896.

(40) Delegan, N.; Pandiyan, R.; Johnston, S.; Dirany, A.; Komtchou, S.; Drogui, P.; El Khakani, M. A. Lifetime Enhancement of Visible Light Induced Photocharges in Tungsten and Nitrogen in Situ Codoped TiO2:WN Thin Films. J. Phys. Chem. C 2018, 122 (10), 5411-5419.

(41) Moniz, S.; Tang, J. Charge Transfer and Photocatalytic Activity in $\mathrm{CuO} / \mathrm{TiO} 2$ Nanoparticle Heterojunctions Synthesised through a Rapid, One-Pot, Microwave Solvothermal Route. Chem. Cat Chem. 2015, 7, 1659-1667.

(42) Van de Walle, C. G.; Neugebauer, J. Universal Alignment of Hydrogen Levels in Semiconductors, Insulators and Solutions. Nature 2003, 423 (1), 626-628.

(43) Lau, V. W.-h.; Moudrakovski, I.; Botari, T.; Weinberger, S.; Mesch, M. B.; Duppel, V.; Senker, J.; Blum, V.; Lotsch, B. V. Towards Rational Design of Carbon Nitride Photocatalysts: Identification of Cyanamide "Defects" as Catalytically Relevant Sites Results \& Discussions. Nat. Commun. 2016, 7, 12165.

(44) Kresse, G.; Furthmuller, J. Efficient Iterative Schemes for Ab Initio Total-Energy Calculations Using a Plane-Wave Basis Set. Phys. Rev. B 1996, 54 (16), 11169-11186.

(45) Blöchl, P. E. Projector Augmented-Wave Method. Phys. Rev. B: Condens. Matter Mater. Phys. 1994, 50 (24), 17953-17979.

(46) Perdew, J. P.; Burke, K.; Ernzerhof, M. Generalized Gradient Approximation Made Simple. Phys. Rev. Lett. 1996, 77 (18), 38653868. 
(47) Grimme, S. Semiempirical GGA-Type Density Functional Constructed with a Long-Range Dispersion Correction. J. Comput. Chem. 2006, 27 (15), 1787-1799.

(48) Walsh, A.; Catlow, C. R. A. Structure, Stability and Work Functions of the Low Index Surfaces of Pure Indium Oxide and SnDoped Indium Oxide (ITO) from Density Functional Theory. J. Mater. Chem. 2010, 20 (46), 10438-10444.

(49) Ruan, Q.; Luo, W.; Xie, J.; Wang, Y.; Liu, X.; Bai, Z.; Carmalt, C. J.; Tang, J. A Nanojunction Polymer Photoelectrode for Efficient Charge Transport and Separation. Angew. Chem., Int. Ed. 2017, 56 (28), 8221-8225. 